Article

\title{
Korean Scholars' Use of For-Pay Editors and Perceptions of Ethicality
}

\author{
Eun-Young Julia Kim $\mathbb{D}$ \\ Department of English, Andrews University, Berrien Springs, MI 49104, USA; keun@andrews.edu
}

Received: 14 November 2018; Accepted: 8 March 2019; Published: 14 March 2019

\begin{abstract}
Many Korean scholars rely on language professionals for preparing English manuscripts. So far, little has been reported on how Korean scholars utilize them and how they perceive various types of help received. This study examines how Korean scholars utilize for-pay editors and translators, and how they perceive various types of textual modifications incurred in the process, based on the data obtained through a survey completed by 88 Korean faculty from three universities. Half of the participants received proofreading help from for-pay editors, and fewer participants received help with translation. They held widely differing views on ethicality concerning scenarios that involved globaland content-level editing; none of the help described was perceived as clearly unethical. This paper argues that as the academic communities benefit from the knowledge and insights created through research conducted by scholars across the world, it is necessary to establish proper boundaries of writing help.
\end{abstract}

Keywords: academic integrity; multilingual scholars; language editors; English as a lingua franca; academic ethics

\section{Introduction}

Increasingly more scholars in non-English speaking countries seek publications in English-medium journals to increase visibility to their studies and/or to meet the demands of their academic institutions, which place a high premium on papers published in high-impact English journals for faculty promotion and tenure. Multilingual scholars, who desire to publish in English-medium journals often seek help from language professionals, are faced with challenges, such as the lack of English language facilities and the lack of knowledge regarding genre and disciplinary conventions [1-3]. Some scholars write their manuscripts in their native language and hire a translator to translate their work into English. Many consider the use of language professionals as appropriate or even essential, and some journals openly encourage receiving help from language professionals, or native English speakers, for scholars who use English as an additional language (EAL). However, the general advice to have the manuscripts reviewed and edited by native English speakers seems to reveal the assumption that the role of editors centers on a narrowly defined set of areas [4,5]. For the EAL scholars who live in non-English speaking countries, native English-speaking peers who can provide such help are not always easily accessible, and for this reason, scholars resort to the for-pay editors and translators who specialize in scholarly publishing.

There is no doubt that the support of these professionals is an important resource for multilingual scholars who seek to publish internationally. And it is likely that as the contribution of multilingual scholars to English-medium journals increases, so will the role of language professionals. For this reason, the nature of the help provided by these professionals warrants a close look because the heavy dependence on editors, translators, and using extended editing services that go beyond proofreading and attending to local errors, can border on authorship encroachment and therefore raise ethical questions.

The current study focuses on the intersection between the involvement of large editing companies and academic integrity by examining how Korean scholars utilize for-pay editors, and how they perceive 
various types of textual alterations incurred in the process based on the data obtained through a survey completed by 88 Korean faculties from three universities. In this paper, the term "for-pay editors" is used synonymously with language professionals and refers to those who provide editing and translation services through large commercial companies based in Korea, such as HARRISCO and Editage, because the use of these companies is common practice among scholars in Korea. These companies offer both editing and translation, and translation often entails editing. Therefore, even though the terms "editor" and "translator" are not used interchangeably in the literature, "for-pay editors" in this paper may include translators who work for large commercial editing companies. Practices by freelance and in-house translators and editors may differ from those of large companies and are outside the purview of this study.

\section{Literature Review}

Lillis and Curry term those who provide assistance to EAL scholars as "literacy brokers" and categorize them into three groups: colleagues who work at the same institution; professional helpers such as translators, proofreaders, and copy editors who make sentence-level edits; and non-professional helpers such as friends and family [6]. Lillis and Curry encouraged scholars to closely examine the processes and experiences non-English speaking authors go through as they work with these literacy brokers for help with linguistic challenges and have a lack of familiarity with the system in general [7]. Various groups of people who provide assistance to the EAL scholars are likely to help with different, albeit overlapping, aspects of a text.

The role of language professionals continues to receive attention from researchers who examine issues surrounding scholars publishing internationally. Despite a somewhat simplified, stereotypical view inherent in the label "language professionals" that their work mainly centers on "cleaning up" grammatical errors and other formal errors, their work encompasses a wide range of areas. They may need to initiate changes at the level of discourse and arguments [8,9], and the revision may involve rephrasing, adding words or phrases, and rearranging details to improve textual cohesion and readability [10]. Also, substantive reworking may be necessary to make the text meet Anglo-American cultural expectations in writing. As noted by several scholars, the nomenclature "language editors" is misleading because the boundary between linguistic form and content is fluid [6,11]. Although assistance received from the language professionals leads to text-transformations at varying degrees [12], the type and level of help received in the process is not always known. Whereas many journals in medicine and health science require disclosure of any assistance received in the manuscript preparation process, journals in other disciplines, including the author's own, typically do not require the same level of transparency in disclosing assistance with the writing and editing.

Language professionals are not the sole providers of help for EAL scholars. As noted by Burrough-Boenisch [8], the writing process for non-native English speaking academics often involves many different actors or shapers. It is through the involvement of these shapers, such as colleagues, editors, reviewers, and copy editors, among others, that a manuscript is gradually transformed and loses most non-native traits. DiGiacomo's [13] case study of an Italian-Spanish bilingual doctoral candidate writing a thesis demonstrated that the notion of authorship is a fluid concept and presents a "signature dilemma" [14] (p. 16). Her study demonstrated that thesis advisers play an integral role as they "intervene significantly in the texts produced by their graduate students." She added, "in no discipline can the measure of authorship be that the student wrote every single word alone and without guidance because the doctoral thesis is the final stage of a professional apprenticeship" [13] (p. 67).

Flowerdew [11] and Lave and Wenger [15] noted that to be accepted into a scholar's academic discourse community, an apprenticeship through "legitimate peripheral participation" is essential, and this apprenticeship involves help from various individuals. It is not just EAL scholars who need or receive help; Anglophone scholars also go through this apprenticeship because legitimate peripheral participation would apply to all novice scholars regardless of the languages they speak. However, help provided to EAL scholars through various shapers or actors has additional dimensions for 
consideration, especially when the help involves substantive reworking of the manuscript to conform to the Anglo-American rhetorical norms and discourse patterns [16].

The availability of helpers or editors and the scholars' accessibility to them can affect the outcome for EAL scholars desiring to publish internationally. For the novice scientists, in mainland China, studied in Li and Flowerdew's study, the shapers mostly involved other EAL speakers including supervisors, peers, and language professionals [17].

The work of language professionals working with EAL academics may also include translation. Some EAL scholars hire a translator to translate manuscripts, prepared in the scholars' first language, into English. But the translator is usually not recognized in the published text, nor does the manuscript reveal that it was originally written in the scholar's first language and was later translated by someone else. The perception that it is not necessary to disclose this information seems to reflect the assumption that translation is a rather straightforward and neutral task. However, translation is not entirely a neutral process because translators often have to make decisions concerning interpretations, and modifications are often made in the process [18]. Also, translators often function as cultural informants to help the client's writing to be accepted in an international scholarly community. To that end, they may need to ensure that the rhetorical patterns align with those that are expected from the English-speaking academic communities and make decisions about nativized or non-idiomatic expressions that may not be understood outside the scholar's language community. Deviance from the target culture discourse norm is perceived as problematic and often as a sign of poor knowledge and ability in academic communities [19,20]. For this reason, it falls on the translator to appropriately encode meanings formed in the scholar's first language into the target language. When the translation is done for publishing in an academic journal, it is likely to involve a fair amount of editing as well, further blurring the boundary between translation and editing. This necessitates "negotiations with authors about particular linguistic formulations long after the translation has been ostensibly completed" [21] (p. 96). In reality, however, this type of negotiation is not always available in commercial editing services $[10,22]$. It can be problematic when there is insufficient consultation with the author [23]. For instance, changes at the lexico-syntactic level can surpass surface level change and entail metafunctional changes, which alter "the position of the scientist and his text in relation to the scientific community" [24] (p. 129).

Whereas several professional organizations clearly define the parameters of authorship, what constitutes encroachment of this authorship is not clear. For example, the Committee of Publication Ethics (COPE) and the International Committee of Medical Journal Editors (ICMJE) make only a brief statement about acknowledging contributors. COPE's document entitled "What constitutes authorship" simply states that "other individuals who have contributed to the study should be acknowledged, but not identified as authors" [25] (p. 2). It also emphasizes that "authorship within the humanities, law, and theology is still very much a product of the writing process, and usually by a single individual" (p. 3). Therefore, "any other form of contribution such as generation of ideas, commenting on a draft, or technical assistance is listed in the Acknowledgments" (p. 3). Neither of these statements from COPE includes specific guidelines, beyond the general notion of acknowledging contributors. Similarly, in the section entitled, "Non-author Contributors," ICMJE states,

Those whose contributions do not justify authorship may be acknowledged individually or together as a group under a single heading (e.g., "Clinical Investigators" or "Participating Investigators"), and their contributions should be specified (e.g., "served as scientific advisors," "critically reviewed the study proposal," "collected data," "provided and cared for study patients," and "participated in writing or technical editing of the manuscript"). [26]

The last phrase, which applies to language professionals, is vague, as the phrase "participated in writing or editing" entails varying levels of involvement of language professionals. A joint statement entitled, "Principles of Transparency and Best Practice in Scholarly Publishing," issued by COPE, Open Access Scholarly Publishers Association (OASPA), the Directory of Open Access Journals (DOAJ), and 
the World Association of Medical Editors (WAME) also limits its scope to identifying general policies about journals, such as peer review process, governing body, author fee, and access, among others. Clear guidelines concerning the acknowledgment of language professionals are not present in the documents of these professional organizations [27].

The issues of authorship encroachment is especially germane to Korean scholars, who are the focus of this study. Currently, a number of academic editing services in Korea provide editing and translation services for academics. Several of them specialize in preparing manuscripts for journals indexed in the Science Citation Index (SCI), Social Science Citation Index (SSCI), and Arts and Humanities Citation Index (A\&HCI), as placing publications in those journals receive a high score on the faculty tenure and promotion process. Some of the popular for-pay editors provide editing and translation services at different levels. For instance, one popular company, Editage, offers three levels of services-general, premium, and premium plus [28]. The last two levels target those who aim to publish in high visibility English journals [29]. The company states that its premium editing addresses concerns related to organization, meaning, logic, formatting, and it includes a cover letter [30]. Another company, HARRISCO, which is one of the largest editing and translation companies, states on its website that it is the designated editing company for 78 universities and around 250 academic institutes and conferences in Korea, and is staffed by hundreds of bilingual and native-English speaking editors from countries such as the U.S., U.K., Canada, Australia, New Zealand, and India, who have master's or doctoral degrees from elite universities [31]. The website also states that for those who aim to publish in journals indexed in SCI, SSCI, and A\&HCI, the company provides full service, including translation, editing, submission, communicating the editor's decision, and consultation after peer reviews [32]. These companies usually have speedy turnarounds, and the process involves multiple editors/translators as the manuscript goes through several drafts of revision. These practices are in line with those seen at other large companies such as Enago and Edanz based in other countries. Enago, for instance, advertises that its services include substantive editing concerning logical flow, presentation, and content enhancement, as well as proofreading and copy editing [33]. Similarly, Edanz advertises that it offers "in-depth edit that improves the structure and flow of your manuscript and ensures the language is of publication quality"; also, the company provides a cover letter and a response letter after peer-review [34].

Some universities have in-house editing services. But others provide faculties with funding for the cost incurred by the use of for-pay editors. The faculty research website at one large, prestigious university in Seoul specifically indicates that funding for using for-pay editors is allowed for the premium-level editing provided by three designated commercial companies: HARRISCO, Editage, and eWorldEditing [35]. Designating large commercial editing companies as recognized sources of help will not only increase the role of those companies, which specialize in publishing in journals indexed in A\&HCI, SSCI, and SCI for Korean scholars publishing internationally, it will also facilitate the notion that it is essential to receive help from these editors who also assume the role of publication experts to place the papers in prestigious journals successfully.

Although other shapers or helpers, such as peers or native-English speaking colleagues, are likely to be involved in the manuscript preparation process as mentioned earlier, the role of these for-pay editors is paramount to many Korean scholars. Some of these for-pay editors claim to specialize in publishing in high impact English journals, and their editing practices may differ from those offered by thesis supervisors, peers, or other helpers. Despite the increased role and expanding service of for-pay editors and translators in the Korean scholarly communities, little has been reported on how Korean scholars utilize them and how they perceive the various types of help received. To help fill this gap, the current study examines how Korean scholars utilize language professionals and perceive various types of textual modifications made by them.

This paper focuses on the following questions:

1. How do Korean academics utilize for-pay editors in academic knowledge production? 
2. How ethical do Korean academics perceive various types of text alteration incurred by the work of for-pay editors in the process of preparing and publishing their manuscripts?

\section{The Study}

Data were obtained from an online survey prepared in Korean using Class Climate [36] for a two-part study. The current study draws from the second part of the study, which focuses on Korean scholars' perceptions and experiences of using for-pay editors and translators. The first part of the study examined how the impact of internationalization of academic knowledge is reflected in the language choice of Korean academic journals and what motivates Korean university faculties to publish in English. The results have been reported in a separate paper [37]. The results from the last three questions about ethics on the survey are reported and discussed in the current study. A link to the survey was sent via email to the teaching faculties at three Korean universities that were randomly chosen among four-year universities that offer academic programs in various disciplines including Humanities, Social Science, Natural Science, Engineering, and Health. Participants' email addresses were obtained from the institutions' websites. Unfortunately, some emails were returned or rejected by the participants' email servers, so it is not possible to know the exact number of participants that received the invitation. A total of 88 faculties completed the survey, including 11 faculties from humanities, 33 from social science, 8 from natural sciences, 30 from engineering, 2 from health, and 4 who did not specify or specified more than one field. Despite the small sample size, the findings from the current study can offer preliminary knowledge to help guide future research to more fully understand the role of for-pay editors in Korean scholars' publishing.

The survey for this part of the study contained two sections. The first section included questions about the participants' practices when utilizing for-pay editors, measured on a Likert scale. The questions asked about the frequencies of using for-pay editors, availability of institutional funding for using them, and the sense of financial burden incurred by the cost. The second section included 6 questions on ethics designed to understand the participants' perceptions on various types of help received from for-pay editors in 6 hypothetical, yet likely scenarios adapted from Kim and LaBianca [38]. Participants were asked to rate 6 different hypothetical scenarios on a 5-point Likert scale (1: ethical, 5: unethical).

The 6 scenarios, categorized into 2 groups, describe different types and levels of help, which become progressively more extensive. The 3 scenarios in the first group describe situations in which a multilingual scholar seeks help with the manuscript which the scholar had written in English him/herself. The three scenarios in the second group describe situations in which the scholar has first written his or her manuscript in their native language before receiving help from for-pay translators as well as textual modifications at various levels. The six scenarios consist of the following:

1. An international scholar prepared his or her manuscript in English. Then, he/she

(1) Submits the draft written in English to a for-pay editor, who proofreads for errors in spelling punctuation, grammar, formatting, citations, and references.

(2) Submits the draft written in English to a for-pay editor, who reorganizes the writing, tightens up the flow of argument, and rephrases sentences for clarity and accuracy, in addition to providing services in Scenario 1.

(3) Submits the draft to a for-pay editor, who makes content-level changes by deleting, adding, and rewriting sentences to correct errors in ideas, reasoning, and explaining/applying theories, in addition to providing services in the previous two scenarios.

2. An international scholar writes the manuscript in his or her language for an English-medium journal. Then he/she

(4) Takes the draft written in his/her language to a for-pay editor, who translates the manuscript into English without making any content changes. 
(5) Submits the draft written in his/her native language to a for-pay editor, who translates the manuscript into English and also reorganizes the writing, tightens up the flow or argument, and rephrases sentences for clarity and accuracy.

(6) Submits the draft written in his/her language to a for-pay editor, who translates the manuscript into English, also making some content changes by deleting, adding, and rewriting sentences to correct errors in ideas, reasoning, and explaining/applying theories.

Since this study sought to examine the participants' perceptions concerning various types and levels of text alterations made in the editing/translating process, the scenarios were worded so that participants could understand that the level of revision in each step progressed from the local level to the global and content-level. It should be noted, however, that the boundary between each level, especially the last two in each set, is somewhat fluid, as tightening up the flow of the argument could also entail correcting errors in ideas. A quantifiable metric, such as the one used by Willy and Tanimoto [39] and Luo and Hyland [40], categorized the levels of textual modification based on the number of words, and therefore, could avoid the problem of overlap. However, in this study, the editing process was presented semantically based on different areas of correction and text modification, and they were worded to present graduated help in terms of rhetorical choices and content, rather than the number of words changed.

\section{Results}

\section{Q1: How do Korean academics utilize for-pay editors and translators in academic knowledge production?}

When asked how often they utilize for-pay editing services, most participants answered "sometimes" (See Table 1). Faculties from the natural sciences indicated more frequent use, whereas those from the humanities indicated the least use. However, the difference across disciplines was not statistically significant. The majority of participants responded that their institutions "occasionally" helped with the cost of using for-pay editing services. This item had the smallest standard deviation among all other items, which indicates that all three Korean universities in this study provide their faculty with funding for using for-pay editing services to a certain level. The mean score for the question concerning whether the expenses incurred by the use of for-pay editors was financially burdensome was 3.5, slanting towards "agree" (See Table 1).

Table 1. Use of For-Pay Editing Services.

\begin{tabular}{cccccccccc}
\hline \multirow{2}{*}{ Fields } & \multicolumn{2}{c}{ Frequency of Using For-Pay Editor } & \multicolumn{3}{c}{ Institutional Funding } & \multicolumn{3}{c}{ Financial Burden } \\
\cline { 2 - 9 } & $\mathbf{N}$ & $\mathbf{M}^{\mathbf{1}}$ & SD & $\mathbf{N}$ & $\mathbf{M}^{\mathbf{2}}$ & SD & $\mathbf{N}$ & $\mathbf{M}^{\mathbf{3}}$ & SD \\
\hline Humanities & 11 & 2.1 & 1.6 & 7 & 2.4 & 0.79 & 10 & 3.3 & 1.3 \\
Social Science & 32 & 3.0 & 1.4 & 27 & 1.9 & 0.73 & 32 & 3.6 & 1.0 \\
Natural Science & 8 & 3.4 & 1.8 & 8 & 2.3 & 0.71 & 6 & 3.0 & 1.5 \\
Engineering $^{4}$ & 30 & 3.1 & 1.5 & 24 & 2.0 & 0.59 & 25 & 3.7 & 0.9 \\
Total $^{4}$ & 81 & 3.0 & 1.5 & 66 & 2.0 & 0.69 & 73 & 3.5 & 1.1 \\
\hline
\end{tabular}

${ }^{1}$ 5: almost always; 4: frequently; 3 : sometimes; 2 : seldom; 1 : never. ${ }^{2}$ 3: most of the time; 2 : occasionally; 1 : never. ${ }^{3}$ 5: strongly agree; 4: agree; 3 : neutral; 2 : disagree; 1 : strongly disagree. ${ }^{4}$ For this part of the analysis, data from two health faculties were excluded due to the small size. Data from two faculties who specified no fields and two who specified more than one field were also excluded.

When asked if they had received help from for-pay editors with local errors, such as proofreading for misspelling, punctuation, grammar, formatting, citations, and references, 50\% of the participants had said yes. Twelve percent indicated that they had received help translating their papers to English from commercial editing companies. Notably, none of the participants from natural science indicated having received help with translation. Twenty-five percent indicated that the type of help they received included reorganizing their writing, tightening up the flow of argument, and rephrasing for clarity 
and accuracy. Three percent received content-level help including deleting, adding, and rewriting sentences to correct errors in ideas, reasoning, and explaining/applying theories.

In sum, half of the Korean scholars at the three universities received proofreading help from for-pay editors. Also, receiving help with higher-order concerns does not seem to be uncommon. The chi-squared tests did not show any statistically significant differences across disciplines and universities in the types of help the participants had received.

Q2: What are Korean scholars' perceptions of various types of text modifications by editors and translators in the process of preparing and publishing their manuscript?

The next group of questions measured participants' perceptions of ethicality concerning various types of help provided by for-pay editors and translators. Participants were asked to rate six different hypothetical scenarios described earlier, on a 5-point Likert scale (1: ethical, 5 unethical).

For the three questions in the first group, participants considered the first two scenarios as ethical. In the first scenario, the help centered entirely on proofreading (See Table 2) and the help in the second scenario expanded to reorganizing, rephrasing, and tightening up the flow of the writing. Notably, the mean score of the third scenario, in which the help involved content level changes made by for-pay editors, aligned to "neutral," rather than to "unethical."

Table 2. Perceptions on Ethicality Concerning Various Types of Help Received.

\begin{tabular}{ccc}
\cline { 2 - 3 } Scenarios & $\mathbf{M}$ & SD \\
\hline $1(n=87)$ & 1.3 & 0.7 \\
$2(n=86)$ & 2.1 & 1.2 \\
$3(n=87)$ & 3.4 & 1.4 \\
$4(n=87)$ & 1.9 & 1.2 \\
$5(n=86)$ & 2.6 & 1.4 \\
$6(n=87)$ & 3.3 & 1.5 \\
\cline { 2 - 3 } Note: The items were measured on a 5-point Likert Scale (1: ethical; 5: unethical).
\end{tabular}

The same pattern is observed in the responses to the three questions from the second group as indicated in Table 2. Having the entire manuscript translated from Korean into English by a for-pay translator, as well as receiving help with reorganizing the ideas in the process of translation, were considered ethical. The mean score for the last scenario, in which the for-pay translator translates, reorganizes, proofreads, as well as makes content-level changes was 3.3, aligning to "neutral" rather than to "unethical." The analysis of covariance showed no statistically significant difference across disciplines in the ratings of these six scenarios.

Another common pattern that was observed was that standard deviations had an upward tendency in both groups of questions, with responses concerning the content level changes showing higher standard deviations. This seems to indicate less certainty and agreement concerning scenarios that border on inappropriate intrusion by the translator or editor. In sum, none of the help described was perceived as clearly unethical.

\section{Discussion}

Internationalization of academic knowledge has enriched, and continues to enrich, academic communities with new knowledge and insights offered by scholars from around the world. As multilingual scholars try to reach their global academic peers, those who provide language help, including for-pay editors and translators, will continue to play an important role.

In the current study, most Korean scholars indicated having received help from for-pay editors. Faculty from the natural sciences indicated more frequent use, while faculty from the humanities indicated the least use. Most of the participants responded that their institutions "occasionally" helped with the cost of using for-pay editing services, and the sense of financial burden slanted toward "agree." 
The relatively low frequency of use of for-pay editors from the humanities faculty likely stems from the fact that they publish in English-medium journals less frequently compared to other disciplines [39]. However, the trend may change in the future, if more humanities faculty find themselves in the same position as the science faculty, who are expected to publish in international journals for promotion and tenure. The fact that the majority of participants responded that their institutions "occasionally" provide funding for the cost incurred by the use of language professionals reveals at least a certain level of institutional support and sanctioning of their practices. Currently, the information regarding the level of financial support provided by the universities for faculty research is publicly available only on one of the three universities from which participants were recruited; based on the information available on the web, the institution provides $\$ 3,000,000$ (approximately $\$ 2700$ ) more for papers targeting journals indexed in A\&HCI, SSCI, SCI, compared to those targeting journals published in Korean [41]. The different amount of monetary support for studies targeting Korean and English journals indicates the zeal on the part of the institutions to make their faculty's research visible to the international community and improve the institutions' reputation. To be sure, this will lead to more Korean faculty submitting and eventually publishing in elite English-medium journals. At the same time, it will result in the asymmetric deposit of knowledge produced in Korean and English and create a knowledge hierarchy produced in the two languages in certain fields. Furthermore, offering significantly greater financial support for publishing in the elite, English-medium journals exacerbates the center-periphery dichotomy, which currently dominates scholarly publishing [37]. However, without fully understanding how much support the other two institutions provide, how much is allotted for using for-pay editors, and whether or not those institutions also promote utilizing large commercial companies, it is not possible to draw clear implications from the findings. Further research is needed to investigate if the sense of burden is greater for faculty teaching at smaller institutions, such as from two of the universities from which the participants were recruited, and what different variables, such as types of institutions, levels of funding, and field of study, affect Korean scholars' use of for-pay editors.

Half of participants received proofreading help; one fourth received help from for-pay editors with higher-order concerns which involved substantive reworking, such as reorganizing and tightening up the flow of the argument; and three percent received content-level help which included alterations to correct errors in ideas, reasoning, and explaining/applying theories. Twelve percent had their papers translated by for-pay editors. The findings of this study confirm what existing studies reviewed earlier indicated; language professionals' roles are multifaceted and encompass a wide range of tasks [4]. Although help provided to address lower-order concerns such as proofreading and issues related to formatting and styles are typically viewed as appropriate, text alteration incurred by for-pay editors involving higher-order concerns and convent-level errors warrants further examination. The high standard deviations shown in some of the more controversial scenarios under the second research question indicate a lack of certainty and consensus among Korean scholars. This highlights the importance of more clearly defining what constitutes ethical help as various language professionals offer assistance to multilingual scholars to make their research accepted by global academic communities.

As noted by Harwood, Austin, and Macaulay [42], and Bennet [21], those who assist with writing often face ethical dilemmas as to what is the appropriate boundary of help. Lack of parameters can cause editors to fail to provide services for fear that they are not within their remit [4]. Alternatively, "some may inadvertently, or indeed ill-advisedly, engage in practices with ethical implications they are unaware of" [8] (p. 3). To be sure, receiving help to prepare a manuscript for publication, whether on lower- or higher-order concerns, would not be a problem in itself. However, when large, profit-oriented, outcome-driven commercial companies are at the helm of the publication process, and the process of negotiation between authors and editors is curtailed to ensure speedy publication, there will be an increased chance the academic integrity will be compromised. That is why it is necessary to establish 
parameters for ethical writing and promote transparency in published articles through acknowledging the type and level of help received from for-pay editors and translators.

Both editing and translation entail much more than simple corrections by a native speaker or a straightforward translation from one language to another. Some scholars have argued that "revision by authors' editors should be put on the same footing as assistance in other aspects of the research (collating data, statistical analyses, etc.) and that authors' editors must therefore be listed as contributors" [8] (p. 233). Scholars have argued, "By acknowledging the role of the language professionals, we see the published text for what it is: a product of the publishing industry, as well as a product of, and for, a particular discourse community" [8] (p. 224). Dueñas observed that in some fields, editorial agencies issued a certificate, stating that the paper has been edited for minor local errors such as "proper English language, grammar, punctuation, spelling, and overall style" but not "research content nor the authors' intentions were altered in any way during the editing process" [43] (p. 149). At the same time, translated work is not usually recognized. Currently, some editing companies in Korea issue a certificate. But it is not known how transparent the information in the certificates is. Some of the editing and translation samples posted on Editage's website show sentences and phrases being deleted and added, as well as extensive wording changes and reorganization, especially at the premium and premium plus level services [44].

This study has offered some new information concerning Korean EAL scholars' use of for-pay editors, but it has several limitations that need to be pointed out. First, it draws from the participants' experiences and perceptions and does not include actual data that show specific types of help they received from for-pay editors. Second, examples are drawn from one large company based on web information, and they cannot be seen as representative of all large editing companies. Third, the study draws from a small sample, and not all disciplines were represented in the sample. The number of respondents from natural science and health was particularly small and the results could have been different if more faculty from those disciplines had participated in the study because academics in medicine, health, and natural science are usually the most productive in terms of publishing in English-medium journals.

Additionally, it should be noted that professional practices may widely differ between large editing companies and individual freelance editors and translators. Therefore, further research is needed to show how higher order concerns and content-level changes are negotiated between Korean scholars and for-pay editors, translators, and other types of language professionals in the editing and translation process.

\section{Conclusions}

This study sought to contribute to ongoing scholarly discussions on the issues surrounding EAL scholars publishing internationally by examining the utilization of for-pay editors among Korean scholars and their perceptions of various levels of textual alteration made by these editors. The study shed some light on these topics, but it also leaves us with other questions. How are higher-order concerns handled by for-pay editors? What are the ethical boundaries of the writing help? And what should be the guiding principles in determining the boundaries? The author's previous study of U.S. faculty and international students' perceptions of various types of writing help showed that they held different views in some areas, but in general, the majority of participants in both groups considered the changes directly made by helpers-be they writing center tutors, peers, faculty help, or for-pay editors-without engaging the writers, as problematic [40]. In light of the current study, it seems contradictory to sanction extensive text alteration done by commercial editors for scholars seeking publication, while we penalize students who submit their class written assignments that have been altered to the same extent by others. Students completing written assignments, as well as faculty preparing manuscripts for publication, should be supported with help whenever available. But it seems problematic that contradicting standards are held between students and faculty for high-stake writing tasks. 
There exists a grey area where determining ethicality and originality is not always clear-cut. This study did not attempt to delineate the boundaries of what constitutes ethical writing help. Rather, the study has sought to make a case for disclosing the type and nature of assistance provided by for-pay editors and translators in a published article. Making the process transparent can be the first step in curbing potentially unethical practices that encroach authorship. In the meantime, all stakeholders, including researchers, editors, translators, as well as journal editors and professional organizations, should engage in a cross-disciplinary scholarly conversation to identify guiding principles that can help us draw ethical boundaries of help. Without them, the integrity of knowledge can be compromised.

Funding: This research received no external funding.

Conflicts of Interest: The author declares no conflict of interest.

\section{References}

1. Canagarajah, S. A Somewhat Legitimate and Very Peripheral Participation. In Writing for Scholarly Publication: Behind the Scenes in Language Education; Casanave, C.P., Vandrick, S., Eds.; Lawrence Erlbaum: Mahwah, NJ, USA, 2003; pp. 197-210.

2. Gea-Valor, M.L.; Rey-Rocha, J.; Moreno, A.I. Publishing Research in the International Context: An Analysis of Spanish Scholars' Academic Writing Needs in the Social Sciences. Engl. Specif. Purp. 2014, 36, 47-59. [CrossRef]

3. Casanave, C.P.; Vandrick, S. Writing for Scholarly Publication: Behind the Scenes in Language Education; Lawrence Erlbaum: Mahwah, NJ, USA, 2003.

4. Burgess, S.; Lillis, T. The contribution of language professionals to academic publication; Multiple roles to achieve common goals. In Supporting Research Writing: Roles and Challenges in Multilingual Settings; Matarese, V., Ed.; Chandos: Oxford, UK, 2013; pp. 1-15.

5. Shaw, O.; Voss, S. The delicate art of commenting: Exploring different approaches to editing and their implications for the author-editor relationship. In Publishing Research in English as an Additional Language: Practice, Pathways and Potentials; Cargill, M., Burgess, S., Eds.; University Adelaide Press: Adelaide, Australia, 2017; pp. 71-86.

6. Lillis, T.; Curry, M.J. Professional academic writing by multilingual scholars: Interactions with literacy brokers in the production of English-medium texts. Writ. Commun. 2006, 23, 3-35. [CrossRef]

7. Curry, M.J.; Lillis, T. Multilingual scholars and the imperative to publish in English: Negotiating interests, demands, and rewards. TESOL Q. 2004, 38, 663-688. [CrossRef]

8. Burrough-Boenisch, J. Shapers of published NNS research articles. J. Second Lang. Writ. 2003, 12, $223-243$. [CrossRef]

9. Shashok, K. Author's editors: Facilitators of science information transfer. Learn. Publ. 2001, 14, $113-121$. [CrossRef]

10. Flowerdew, J.; Wang, S.H. Author's editor revisions to manuscripts published in international journals. J. Second Lang. Writ. 2016, 32, 39-52. [CrossRef]

11. Flowerdew, J. Discourse community, legitimate peripheral participation, and the nonnative-English-speaking scholar. TESOL Q. 2000, 34, 127-150. [CrossRef]

12. Flowerdew, J.; Li, Y. The globalization of scholarship: Studying Chinese scholars writing for international publication. In Writing in Foreign Language Contexts: Learning, Teaching, and Research; Manchón, R.M., Ed.; Multilingual Matters: Bristol, UK, 2009; pp. 156-182.

13. DiGiacomo, S.M. Academic advising, authors' editing and translation in a graduate degree program. In Publishing Research in English as an Additional Language: Practice, Pathways and Potentials; Cargill, M., Burgess, S., Eds.; University Adelaide Press: Adelaide, Australia, 2017; pp. 55-70.

14. Geertz, C. Works and Lives: The Anthropoloogist as Author; Stanford University Press: Stanford, CA, USA, 1988.

15. Lave, J.; Wenger, E. Situated Learning: Legitimate Peripheral Participation; Cambridge University Press: Cambridge, UK, 1991.

16. Koyalan, A.; Mumford, S. Changes to English as an Additional Language writers' research articles: From spoken to written register. Engl. Specif. Purp. 2011, 30, 113-123. [CrossRef] 
17. Li, Y.; Flowerdew, J. Shaping Chinese novice scientists' manuscripts for publication. J. Second Lang. Writ. 2007, 16, 100-117. [CrossRef]

18. DiGiacomo, S.M. Giving authors a voice in another language through translation. In Supporting Research Writing: Roles and Challenges in Multilingual Settings; Matarese, V., Ed.; Chandos Publishing: Oxford, UK, 2013; pp. 107-120.

19. Canagarajah, A.S. A Geopolitics of Academic Writing; University of Pittsburgh Press: Pittsburgh, PA, USA, 2002.

20. Lillis, T.; Curry, M.J. Academic Writing in a Global Context: The Politics and Practices of Publishing in English; Routledge: London, UK; New York, NY, USA, 2010.

21. Bennett, K. The translator as cultural mediator in research publication. In Supporting Research Writing: Roles and Challenges in Multilingual Settings; Matarese, V., Ed.; Chandos Publishing: Oxford, UK, 2013; pp. 93-106.

22. Bisaillon, J. Professional editing strategies used by six editors. Writ. Commun. 2007, 24, 295-322. [CrossRef]

23. Ventola, E.; Mauranen, A. Non-native writing and native revising of scientific articles. In Functional and Systemic Linguistics: Approaches and Uses; Ventola, E., Ed.; Mouton de Gruyter: Berlin, Germany, 1991; pp. 457-492.

24. Englander, K. Revision of scientific manuscripts by non-native English-speaking scientists in response to journal editors' language critiques. J. Appl. Linguist. 2009, 3, 129-161. [CrossRef]

25. Committee on Publication Ethics. What Constitutes Authorship? COPE Discussion Document. Available online: https:/ / publicationethics.org/files/Authorship_DiscussionDocument.pdf (accessed on 18 January 2019).

26. International Committee of Medical Journal Editors. Defining the Role of Authors and Contributors. Available online: http:/ / icmje.org/recommendations/browse/roles-and-responsibilities/defining-the-roleof-authors-and-contributors.html (accessed on 18 January 2019).

27. Committee on Publication Ethics. Principles and Transparency and Best Practice in Scholarly Publishing. Available online: https:/ / publicationethics.org/resources/guidelines-new/ principles-transparency-andbest-practice-scholarly-publishing (accessed on 18 January 2019).

28. Editage. Fee for English Editing. Available online: https://www.editage.co.kr/payment/fees.html (accessed on 10 November 2018).

29. Editage. Editage English Editing. Available online: https://www.editage.co.kr/editing/ (accessed on 10 November 2018).

30. Editage. Premium Editing. Available online: https://www.editage.co.kr/editing/pes.html (accessed on 10 November 2018).

31. Harrisco. Information about Editing Services. Available online: http://www.harrisco.net/correction/ correction01.php (accessed on 10 November 2018).

32. Harrisco. Assistance for Overseas Journals. Available online: http://www.harrisco.net/journal/journal01. php (accessed on 10 November 2018).

33. Enago. Substantive Editing. Available online: https://www.enago.com/services/proofreadingediting.htm?gclid=Cj0KCQiAm5viBRD4ARIsADGUT26jAWJFHw8MQf-uhWwyZ1H52t5OmD40UmvnqoGnxggOU1P_nNSMcQaAhATEALw_wcB (accessed on 22 January 2018).

34. Edanz. Expert Editing. Available online: https://www.edanzediting.com/ (accessed on 22 January 2018).

35. Chung-Ang University. Support for Research: Editing Foreign Language Manuscripts. Available online: https:/ / rsch.cau.ac.kr/system/system_a06.html?sm=0\&sm2=5 (accessed on 22 January 2018).

36. Class Climate. Available online: https://www.andrews.edu/classclimate/indexeva.php (accessed on 22 January 2018).

37. Kim, E. Scholarly publishing in Korea: Language, perception, practice of Korean university faculty. Publ. Res. Q. 2018, 34, 554-567. [CrossRef]

38. Kim, E.; LaBianca, A. Ethics in academic writing help for international students in higher education: Perceptions of faculty and students. J. Acad. Ethics 2018, 16, 39-59. [CrossRef]

39. Willey, I.; Tanimoto, K. "Convenience Editing" in action: Comparing English teachers' and medical professionals' revisions of a medical abstract. Engl. Specif. Purp. 2012, 31, 249-260. [CrossRef]

40. Luo, N.; Hyland, K. Intervention and revision: Expertise and interaction in text mediation. Writ. Commun. 2017, 34, 414-440. [CrossRef]

41. Dankook University. Institutional Funding for Research. Available online: http://www.dankook.ac.kr/ web/kor/-365 (accessed on 22 January 2019). 
42. Harwood, N.; Austin, L.; Macaulay, R. Proofreading in a UK university: Proofreaders' beliefs, practices, and experiences. J. Second Lang. Writ. 2009, 18, 166-190. [CrossRef]

43. Mur Dueñas, P. Getting Research Published Internationally in English: An Ethnographic Account of a Team of Finance Spanish Scholars' Struggles. Iberica 2012, 24, 139-156.

44. Editage. Available online: https://www.editage.co.kr/files/PES_edit_medicine.pdf\#page=1\&zoom=100 (accessed on 10 November 2018). 